\title{
microRNA signature for human pancreatic cancer invasion and metastasis (Review)
}

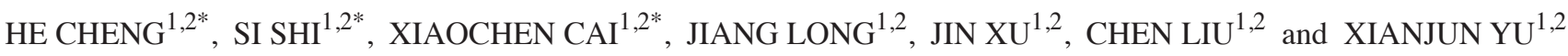 \\ ${ }^{1}$ Department of Pancreatic and Hepatobiliary Surgery, Fudan University, Shanghai Cancer Center; \\ ${ }^{2}$ Department of Oncology, Shanghai Medical College, Fudan University, Shanghai 200032, P.R. China
}

Received March 22, 2012; Accepted May 14, 2012

DOI: $10.3892 /$ etm.2012.585

\begin{abstract}
Pancreatic cancer has the poorest prognosis among all human malignant solid tumors, mainly due to its high invasive and metastatic biological features. microRNAs (miRNAs) are a group of endogenous and small non-coding RNA molecules 18-25 nucleotides in length, functioning as either tumor-suppressor genes or oncogenes. Evidence has shown that regulation of miRNAs in pancreatic cancer is associated with tumor growth, invasion, metastasis and resistance to therapy. Over the last decade, many studies have also found that there is a close relationship between miRNAs and biological characteristics of pancreatic cancer invasion and metastasis, such as the presence of cancer stem cells, epithelial-mesenchymal transition (EMT) phenotype, DNA methylation or epigenetic alteration, and the activation of some specific signaling pathways. Therefore, better understanding of the complex role of miRNAs in the development and progression of pancreatic cancer metastasis may provide new insights that could be of therapeutic consequence. In this brief review, we discuss the literature concerning the correlation between miRNAs and pancreatic cancer, focusing on miRNAs that contribute to pancreatic cancer invasion and metastasis, particularly on cancer stem cell characteristics, the EMT process, epigenetic modifications and tumor-associated signaling pathways.
\end{abstract}

\section{Contents}

1. Introduction

2. microRNAs contribute to pancreatic cancer invasion and metastasis

Correspondence to: Professor Xianjun Yu or Dr Chen Liu, Department of Pancreatic and Hepatobiliary Surgery, Fudan University, Shanghai Cancer Center, and Department of Oncology, Shanghai Medical College, Fudan University, No. 270 DongAn Road, Shanghai 200032, P.R. China

E-mail: yuxianjun88@hotmail.com

E-mail: blurlc@hotmail.com

${ }^{*}$ Contributed equally

Key words: microRNAs, metastasis, pancreatic cancer
3. microRNAs and epithelial to mesenchymal transition

4. microRNAs and cancer stem cells or tumor initiating cells

5. microRNAs and tumor-associated signaling pathways

6. microRNAs and epigenetic alterations

7. Conclusion

\section{Introduction}

Pancreatic cancer is the fourth most common cause of cancerrelated death with 43,140 new diagnoses and 36,800 deaths during 2010 in the US (1). Surgical resection is currently the only curative option for pancreatic cancer, however, due to unusual biological property, high invasive ability and early metastatic feature, only $\sim 15$ to $20 \%$ of tumors can be surgically removed when diagnosed. Even after radical resection, recurrence and metastasis occur within 1-2 years in the majority of cases and the prognosis remains poor (2). Therefore, there is a growing need to deeply understand the mechanisms of the invasive and metastatic profile of pancreatic cancer, which may ultimately lead to an improvement in the prognosis of this fatal disease.

microRNAs (miRNAs) are a class of natural small noncoding RNAs that target protein-coding mRNAs at the post-transcriptional level $(3,4)$. Wightman and coworkers discovered the first miRNA in Caenorhabditis elegants in 1993 (5), and in 2000 the second miRNA, let-7, was found in the same species (6). Abnormal expression of miRNAs is fundamental to the development and progression of various cancers based on their involvement in basic cellular functions. The link between miRNAs and cancer was firstly demonstrated in 2002 by Calin et al (7), who found that miR-15 and miR-16 were involved in the pathogenesis of chronic lymphocytic leukemia. Subsequently, the critical role of miRNA in cancer initiation and progression has been reported in various cancers including pancreatic cancer (8-10). It was also demonstrated that there is a significantly different miRNA expression profile in metastatic carcinomas compared to non-metastatic tumors, and these metastasis-related miRNAs also significantly correlate with the survival of patients (11). Therefore, interference with the expression of these miRNAs may affect tumor metastasis and improve prognosis. In this review, we summarize several important miRNAs in pancreatic cancer progression, highlighting recent advances in elucidating the role of miRNAs in pancreatic cancer invasion and metastasis. 


\section{2. microRNAs contribute to pancreatic cancer invasion and metastasis}

The role of miRNAs in the development of tumor invasion and metastasis was not discovered until 2007. Ma et al (12) reported that miR-10b initiated breast cancer invasion and metastasis. Subsequently, the important role of miRNA in cancer invasion and metastasis in various human malignant tumors, including liver, prostate, lung and colorectal cancers has been reported (13-17). In recent years, various miRNAs have also been found to play a significant role in pancreatic cancer invasion and metastasis. miR-21, which is strongly overexpressed in pancreatic cancer, has been proven to be an 'oncogene' miRNA and its high expression was found to contribute to poor overall survival and chemotherapy resistance $(18,19)$. It has also been reported that miR-21 modulates pancreatic cancer cell growth and invasion. Pancreatic cancer cells transfected with miR-21 precursor were found to exhibit apparently increased cancer cell proliferation and invasion. Conversely, inhibition of miR-21 has an opposite outcome. Furthermore, the level of metastasis-related genes, matrix metalloproteinase-2 and -9, and vascular endothelial growth factor were positively correlated with miR-21 expression, suggesting that MMP-2, MMP-9 and VEGF are 'indirect' target genes of miR-21 (20).

miR-146a has been found to be silent in multiple human cancers, and restoration of its expression can reduce the metastatic potential of cancer cells through suppression of IRAK-1 and subsequent inhibition of NF- $\mathrm{B}$ activity $(15,21,22)$, which is activated in a number of human cancers and involved in promoting tumor development, invasion and metastasis $(23,24)$. In pancreatic cancer, miR-146a is also downregulated, and re-expression of miR-146a inhibits the invasive capacity of pancreatic cancer cells. Notably, a number of studies have indicated that the natural dietary compounds 3,3'-diindolylmethane (DIM) or isoflavone may upregulate miR-146a and inhibit cancer cell invasion. Further mechanistic analysis suggests that miR-146a regulates a set of genes and suppresses cancer cell invasion and migration through targeting EGFR and IRAK-1 (25). Another study also revealed that miR-146b-5p was significantly downregulated in human pancreatic cancer cells, and overexpressed miR-146b-5p notably reduced the abilities of invasion and migration of MIAPaCa-2 pancreatic cancer cells by targeting MMP-16 (26).

In addition, miR-27a is abnormally upregulated in pancreatic adenocarcinoma and inhibition of miR-27a was found to suppress the growth, colon formation and migration of pancreatic cancer cells by targeting Sprouty2, which is an antagonist of the RAS/MAPK signaling pathway in cancers (27). More recently, Yu et al (28) reported that re-expression of miR-200c appeared to be associated with upregulation of E-cadherin, a gene known to be involved in inhibiting the invasion of pancreatic cancer cells. Wang et al (29) identified that miR-520h downregulated ABCG2 in pancreatic cancer cells to inhibit migration, invasion and side population, and indicated that it could be a potential therapeutical target for pancreatic cancer. Preis et al (30) found that miR-10b was overexpressed in pancreatic ductal adenocarcinoma tissues and lower levels of miR-10b were linked with improved response to neoadjuvant therapy, delayed time to metastasis and increased survival. Srivastava et al (31) reported that the level of miR-150 was significantly lower in pancreatic tumors compared with matched normal pancreas tissue. Furthermore, ectopic expression of miR-150 significantly inhibited pancreatic cancer cell invasion and migration as well as tumor growth by suppressing the MUC4 gene in vitro. Other miRNAs have also been reported to play an important role in pancreatic cancer cell invasion and migration, such as miR-17-5p, miR-29a and miR-20a (32-36). Results from these studies may provide an opportunity to carry out miRNA-based therapeutic intervention for pancreatic cancer metastasis (Table I).

\section{3. microRNAs and epithelial to mesenchymal transition}

The epithelial to mesenchymal transition (EMT) is a process by which epithelial cells lose their polarity and are converted to a mesenchymal phenotype, which is regarded as a critical event in morphogenetic changes during embryonic development, wound healing and malignant tumor progression $(37,38)$. This process is accompanied by detachment of cells from each other and subsequent increased cell movement and dissemination. Increasing evidence shows that aberrant activation of EMT is a trigger of malignant tumor invasion and metastasis in various human cancers (39-41). The transcriptional repressor zinc-finger E-box binding homeobox 1 (ZEB1), a crucial inducer of EMT, was recently shown to promote cancer invasion and metastasis in vitro and in vivo (42). Furthermore, members of the miR-200 family (miR-200a, miR-200b, miR200c, miR-141) induce epithelial differentiation through direct targeting of ZEB1 and ZEB2 (43) whereas ZEB1 was reported to directly suppress the transcription of two members of the miR-200a family (miR-200c and miR-141). Therefore, several researchers suggest that there is a feedforward loop between the miR-200 family and ZEB1, which promotes EMT and invasion in cancer cells (44).

Notably, this feedforward loop also exists in pancreatic cancer. Wellner et al (45) reported that expression of miR200c and miR-203 is low in pancreatic cancer, while ZEB1 is overexpressed. In vitro, silencing of ZEB1 by RNA interference in PANC-1 and MIA-PaCa-2 cell lines resulted in an epithelial transition. In orthotopic xenograft models, injection of ZEB1-knockdown cell clones resulted in smaller primary tumors and less invasion and distant metastasis than the control group. In another study, the level of the miR-200 family was found to be significantly low in gemcitabine-resistant cancer cells, which showed a typical EMT characteristic, and re-expression of miR-200 could be essential for the reversal of the EMT phenotype, and thus inhibit cancer cell invasion and metastasis through increasing the epithelial marker E-cadherin expression and suppressing the expression of ZEB1, slug and vimentin. Furthermore, the natural agent B-DIM and isoflavone may also significantly upregulate the expression of let-7, which is known as a tumor-suppressor miRNA $(46,47)$, consequently inhibiting pancreatic cancer progression by reversing EMT characteristics (48) (Fig. 1).

In summary, the expression of various miRNAs may affect EMT characteristics, whereas the EMT process is necessary for the invasion and metastasis of pancreatic cancer. Therefore, identification of the aberrant expression of these miRNAs may provide insight concerning important mechanisms that contribute to pancreatic cancer development and progression. 
Table I. Pancreatic cancer invasion and metastasis-related miRNAs.

\begin{tabular}{|c|c|c|c|c|}
\hline miRNA & Up/downregulated & Potential target & Materials & Reference \\
\hline miR-21 & Up & $\begin{array}{l}\text { MMP-2, MMP-9, } \\
\text { VEGF }\end{array}$ & $\begin{array}{l}\text { PANC-1, AsPC-1, } \\
\text { CFPAC-1, SUIT-2 }\end{array}$ & $(20)$ \\
\hline $\operatorname{miR}-146 a$ & Down & $\begin{array}{l}\text { EGFR, NF-кB, } \\
\text { MTA-2, IRAK-1 }\end{array}$ & Colo357, PANC-1 & $(25)$ \\
\hline miR-146b-5p & Down & MMP16 & MIA-PaCa and FFPE & (26) \\
\hline $\operatorname{miR}-27 a$ & $\mathrm{Up}$ & Spry2 & PANC-1, MIA-PaCa-2, FFPE & $(27)$ \\
\hline $\operatorname{miR}-200 \mathrm{c}$ & Down & E-cadherin & FFPE, SUIT-2, KP-3, PANC-1 & (28) \\
\hline miR-520h & $\mathrm{Up}$ & ABCG2 & PANC-1 & (29) \\
\hline $\operatorname{miR}-10 b$ & Up & $\mathrm{nc}$ & FFPE, EUS-FNA sample & $(30)$ \\
\hline $\operatorname{miR}-150$ & Down & MUC4 & Panc10.05, HPAF, Colo357 & $(31)$ \\
\hline miR-17-5P & Up & nc & FFPE, SUIT-2, KP-2 & $(32)$ \\
\hline $\operatorname{miR}-29 a$ & Down & nc & PANC-1 & $(33)$ \\
\hline $\operatorname{miR}-20 a$ & Uown & Stat3 & PANC-1, BxPC-3 & (34) \\
\hline $\operatorname{miR}-126$ & Down & ADAM9 & $\begin{array}{l}\text { PANC-1, ASPC-1, FFPE, } \\
\text { FNA }\end{array}$ & $(35)$ \\
\hline $\operatorname{miR}-26 a$ & Down & HMGA1 & PANC-1, Sw1990, nude mice & (36) \\
\hline miR-96 & Down & KRAS & $\begin{array}{l}\text { MIA-PaCa- } 2, \text { PANC-1, } \\
\text { FFPE, nude mice }\end{array}$ & (78) \\
\hline
\end{tabular}

MMP-2, matrix metalloproteinase-2; MMP-9, matrix metalloproteinase-9; VEGF, vascular endothelial growth factor; EGFR, epidermal growth factor receptor; NF- $\kappa$ B, nuclear factor $\kappa$ B; MTA-2, metastasis-associated protein 2; IRAK-1, interleukin 1 receptor associated kinase 1; MMP16, matrix metalloproteinase-16; Spry2, Sprouty2; ABCG2, breast cancer resistance protein; MUC4, mucin 4; Stat3, transcription proteins 3; ADAM9, disintegrin and metalloproteinase domain-containing protein 9; HMGA1, high mobility group A 1; KRAS, v-Ki-ras2 Kirsten rat sarcoma viral oncogene homolog; nc, not clear.

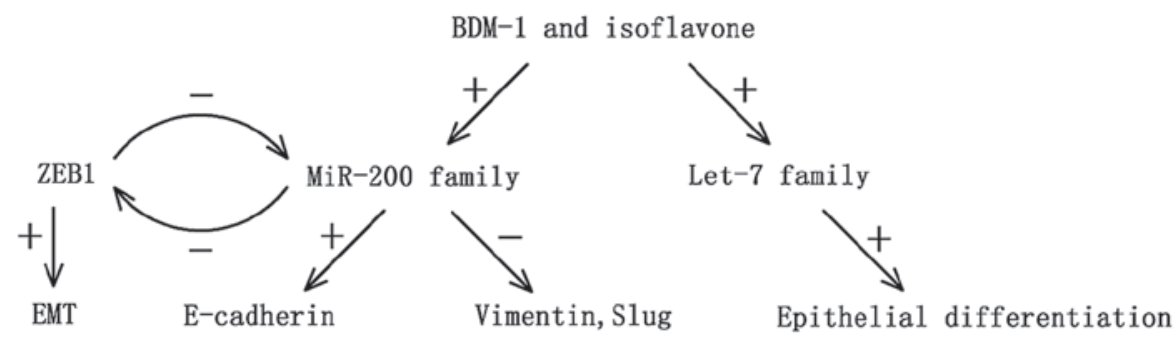

Figure 1. The feedforward loop between miRNAs and ZEB1 in pancreatic cancer.

\section{4. microRNAs and cancer stem cells or tumor-initiating cells}

Cancer stem cells (CSCs) or tumor-initiating cells are a small population of cells within a tumor that initiate proliferation, possess the capacity for self-renewal and ensure multilineage differentiation. The presence of CSCs is considered as the origination of various malignant biological behaviors in human cancers, especially involved in cancer cell migration, invasion and metastasis (49). CSCs were initially discovered in myeloid leukemia cells by Bonnet and Dick (50) in 1997. Subsequently, the existence of CSCs was verified in various cancers, including breast, colorectal and brain cancer (51-53). In 2007, a small subset of highly tumorigenic cancer cells with the cell surface markers CD44, CD24, epithelial-specific antigen (ESA) triplepositive expression, was found in human pancreatic cancer cells (54), which was proven to possess the characteristics of CSCs. Meanwhile, a subpopulation of $\mathrm{CD} 133^{+}, \mathrm{CXCR} 4^{+}$pancreatic cancer stem cells was verified and confirmed to be essential for tumor metastasis (55). Furthermore, $\mathrm{CD}_{133^{+}}$pancreatic cancer cells were also found to be related with increased cell proliferation, migration and invasion (56). All of these findings indicate that the presence of CSCs is responsible for the high invasive and metastatic phenotype of pancreatic cancer.

As discussed above, there is a feedforward loop between the miR-200 family and ZEB1 that promotes EMT and invasion in pancreatic cancer cells. It has also been reported that 
Table II. miRNAs and pancreatic cancer stem cell markers.

\begin{tabular}{llll}
\hline $\begin{array}{l}\text { Up/down- } \\
\text { miRNA }\end{array}$ & \multicolumn{1}{c}{$\begin{array}{c}\text { Related stem } \\
\text { cell markers }\end{array}$} & Materials \\
\hline $\begin{array}{l}\text { miR-200 family } \\
\text { and miR-203 }\end{array}$ & Down & ZEB1 & $\begin{array}{l}\text { MIA-PaCa-2, BxPC-3, } \\
\text { miR-200a, let-7 }\end{array}$ \\
$\begin{array}{llll}\text { and miR-144 } \\
\text { miR-34 }\end{array}$ & Down & DCAMKL-1 & AsPC-1, BxPC-3 \\
miR-101 & Down & CD133/CD44 & MIA-PaCa-2, BxPC-3 \\
& Down & EZH2, EpCAM, Nanog, & MIA-PaCa-2
\end{tabular}

ZEB1, zinc finger E-box binding homeobox 1; DCAMKL-1, doublecortin and CaM kinase-like-1; EZH2, enhancer of zeste homolog 2; EpCAM, epithelial cell adhesion molecule; Nanog, Nanog homeobox; Sox2, SRY-box containing gene 2.

ZEB1 promotes EMT activation and maintains the stemness of cancer cells by suppressing the miR-200 family and miR-203, which is also known as a stemness-inhibiting miRNA, consequently promoting pancreatic cancer invasion and metastasis. In addition, the miR-200 family and miR-203 were found to suppress the expression of 'stem cell factors' such as Sox2, Kif4 and the polycomb repressor Bmi-1 in cancer cells (45). These data suggest that the miR-200 family and miR-203 may prevent pancreatic cancer invasion and metastasis not only by reversion of epithelial to mesenchymal transition, but also by suppressing cancer stem cells.

DCAMKL-1, a microtubule-associated kinase expressed in post-mitotic neurons, is upregulated in human pancreatic cancer and was identified as a putative cancer stem cell marker (57). Silencing of DCAMK-1 in pancreatic cancer cells resulted in suppression of snail, slug, twist and upregulation of miR-200a, which inhibits EMT by repressing the transcription factor ZEB1 and ZEB2 with subsequent rescue of E-cadherin, a marker of epithelial lineage. It was also suggested that DCAMKL-1 regulates epithelial-mesenchymal transition through a miR-200a-dependent mechanism, contributing to pancreatic cancer development, invasion and metastasis. In addition, it was found that DCAMKL-1 knockdown resulted in downregulation of c-Myc and KRAS through a let-7a miRNA-dependent mechanism, and inhibition of the Notch-1 pathway by upregulation of miR-144 (58). These results suggest that miRNAs may modulate tumor stem cell properties by regulating their target or related genes.

miR-34 was identified as a p53 target and a tumor-suppressor miRNA $(59,60)$. It has been reported that miR-34 is involved in pancreatic cancer stem cell self-renewal and differentiation. In addition, restoration of miR-34 significantly inhibited the p53-mutant human pancreatic cancer cell growth and invasion and finally led to an $87 \%$ reduction in the $\mathrm{CD} 133^{+} / \mathrm{CD} 44^{+}$tumorinitiating cell population. Furthermore, miR-34 was found to inhibit its target genes Notch and Bcl-2, 'stem cell genes' to achieve a reduction in cancer stem cells (61). A similar function of miR-34 has also been reported in gastric cancer (62). In addition, it was reported that the curcumin analogue CDF may attenuate EZH2 and other cancer stem cell marker genes, such as Nanog, CD44 and EpCAM through upregulation of tumor-suppressive miRNAs (miR-26a, miR-101, miR-146a, miR-200b and c, let-7a, b, c and d), thus decreasing cell growth, clonogenicity, cell migration and the elimination of CSCs (63).

It is possible that there is a unique miRNA signature responsible for the maintenance and enrichment of cancer stem cells. These stem cell-specific miRNAs may influence pancreatic cancer invasion and metastasis by regulating the 'stemness' and also may provide a potential therapeutic target for pancreatic cancer metastasis (Table II).

\section{5. microRNAs and tumor-associated signaling pathways}

It is well known that various signaling pathways such as Notch, hedgehog and $\mathrm{Wnt} / \beta$-catenin are dysregulated in human carcinomas including pancreatic cancer consequently contributing to tumor development and progression. It has also been shown that several miRNAs appear to possess various essential functions in cancer invasion and metastasis through regulating important signaling pathways. Therefore, the interaction between miRNAs and tumor progression-related signaling pathways in human cancer must be elucidated in detail.

The Notch signaling pathway has been well-documented to be involved in the regulation of numerous cellular process, including cell proliferation, apoptosis, differentiation, invasion and metastasis $(64,65)$. The Notch pathway has been reported to play both oncogenic and tumor-suppressor roles in multiple human cancers (66-68). In pancreatic cancer, the Notch signaling pathway is frequently deregulated with upregulated expression of Notch receptors and their ligands, and functions as an oncogene during tumor growth and progression (69). This is thought to be related to the absence of miR-34. As discussed above, in $\mathrm{CD} 44^{+} / \mathrm{CD} 133^{+} \mathrm{MIA}-\mathrm{PaCa}-2$ cancer stem cells with high Notch/Bcl-2 levels, miR-34 restoration significantly inhibits tumor growth and formation in vitro and in vivo. It has also been reported that miR-34 is silent in pancreatic cancer, and restoration of miR-34 expression in pancreatic cancer cell lines MIA-PaCa-2 and Bxpc-3 downregulates the expression of Bcl-2 and Notch1/2, subsequently inhibiting clonogenic cell growth and cell invasion (61). Recently, Nalls et al (70) reported that upregulation of miR-34a by 5-Aza-dC and HDAC inhibitor vorinostat (SAHA) in pancreatic cancer cells suppressed the 


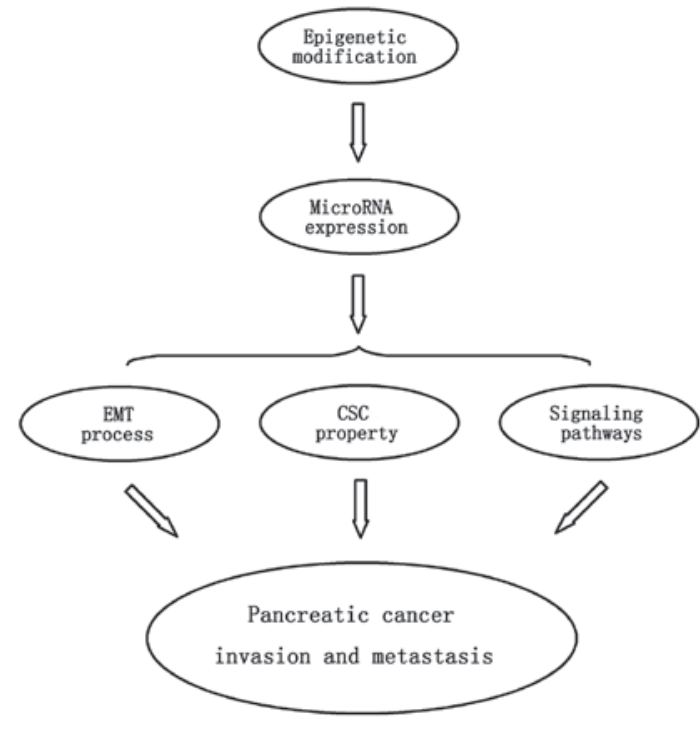

Figure 2. Abnormal expression of miRNAs with epigenetic modification contributes to pancreatic cancer invasion and metastasis through regulation of the EMT process, cancer stem cell properties and signaling pathways.

cell proliferation, cell cycle progression, cell self-renewal, cell invasion and EMT process. Moreover, re-expression of miR-34 by SAHA in pancreatic cancer stem cells inhibited the mRNA expression of all the components of the Notch pathway, including Notch receptor, Notch-1, Notch-3, its ligand Jagged 1 and Notch target gene Hes1; thus miR-34a may inhibit cancer invasion and progression by targeting the Notch signaling pathway (70). In addition, overexpression of Notch-1 in AsPC-1 cells leads to increased cell growth, invasion, clonogenicity, migration, induction of EMT phenotype and decreased expression of miR-200a, miR-200c, let7a, let7b and let7c, while re-expression of miR$200 \mathrm{~b}$ attenuates the acquisition of the EMT phenotype in large part due to the downregulation of the expression of Notch-1 in Notch-1-overexpressed AsPC-1 cells (71).

The Sonic hedgehog (Shh) pathway is aberrantly activated and plays a decisive role in the development and progression of multiple human cancers (72). In contrast, the blockage of the hedgehog pathway could inhibit cancer invasion and metastasis in vivo (73). Increasing evidence supports the possibility that there is an inner link between miRNAs and the hedgehog signaling pathway in human cancers $(74,75)$. It was reported that certain miRNAs activate the hedgehog signaling pathway by targeting Smo, Cos 2 and Fu in Drosophila, which are antagonistic components of the hedgehog pathway (76). Moreover, Tsuda et al (77) reported that synthetic Gli-1-miRNA-3548 and its corresponding Duplex-3548 inhibited cell division and stimulated apoptosis of MIA-PaCa-2 cells through targeting of the Gli-1 gene which controls the pathway of Shh signaling; this suggests that Gli-1 inhibition with miRNA may be a potentially novel approach to pancreatic cancer therapy.

Moreover, miRNAs promote pancreatic cancer invasion and metastasis through the regulation of other tumor associated signaling pathways including RAS, TGF- $\beta$ and NF-кB. For example, ectopic expression of miR-96 inhibited pancreatic cancer invasion and migration with KRAS downregulation in vitro and in vivo, and miR-96 was identified as a core regulator of the KRAS/AKT pathway (78).
These studies suggest that various miRNAs play key roles in multiple signal pathways that are responsible for pancreatic cancer invasion and metastasis, and these miRNAs are essential for the unique metastatic characteristics of pancreatic cancer.

\section{6. microRNAs and epigenetic alterations}

Epigenetic modification such as DNA hypermethylation could have a great impact on the expression of miRNAs, and thus contribute to cancer development and progression. Frequent DNA methylation of cytosine-phospho-guanine (-CpG) island regions adjacent to miR-34a and miR-34b/c, the direct p53 target genes, was observed in various human malignant tumors, including colorectal, prostate and pancreatic cancer, which may mediate cancer cell apoptosis, cell cycle arrest and senescence (79). Epigenetic silencing of miR-107 contributes to MIA-PaCa-2 and PANC-1 cell growth through regulating the expression of cyclin-dependent kinase 6 (CDK-6), which is a cyclin-D1-dependent kinase facilitating cell cycle progression by regulating the activity of tumor-suppressor protein $\mathrm{Rb}$ (80). In addition, the epigenetic inactivation of miRNAs can be reversed by treatment with the DNA demethylating agent, 5-aza-2,-deoxycytidine (DAC) and the histone deacetylase inhibitor, trichostatin A (TSA) (81). Thus, it is possible that aberrant miRNA epigenetic alterations could also play a vital role in pancreatic cancer invasion and metastasis. Recently, miR-224 and miR-486 were found to be significantly overexpressed with epigenetic alterations in highly invasive and metastatic pancreatic cancer, while protein expression of the cell surface marker CD40, a member of the tumor necrosis factor family related to anti-tumor immune responses, was low $(82,83)$. Thus, miRNA-regulated CD40 expression seems to be essential for pancreatic cancer invasion and the process of metastasis (84).

EP-300 is a group of proteins that function as transcriptional coactivators and are also involved in tumor development and progression $(85,86)$. By using 16 human PDAC cell lines in a murine orthotopic PDAC model, Mees et al (87) reported that epigenetic alterations with upregulation of miR-184, miR-200b, miR-200c and miR-429, which target EP300, are likely to cause downregulation of EP300 mRNA and protein expression in highly metastatic PDAC cell lines. The authors also indicated that miRNAs may be able to affect metastatic behavior of pancreatic cancer by modulating the expression of metastasis-related suppressor genes, such as EP-300 (87).

In summary, the expression of various specific miRNAs functioning as tumor-suppressor genes or oncogenes may be regulated by epigenetic modifications such as DNA methylation, finally contributing to pancreatic cancer progression and metastasis. As previously mentioned, differential expression of miRNAs may affect the EMT process, cancer stem cell properties and specific tumor signaling pathways, which may ultimately modulate cancer invasion and metastasis. Therefore, the epigenetic modification responsible for abnormal expression of miRNAs in pancreatic tumors may be a crucial mechanism contributing to cancer invasion and metastasis (Fig. 2).

\section{Conclusion}

Although knowledge concerning the role of miRNA in the regulation of cancer development and progression has been greatly 
advanced since the first discovery of miRNA nearly 18 years ago, the details of miRNA-specific molecular pathogenesis of pancreatic cancer still remain to be elucidated. Recent studies suggest that a variety of miRNAs are frequently dysregulated in pancreatic cancer and have a crosstalk with various important biological processes including DNA methylation, the presence of cancer stem cells, the process of EMT and associated signaling pathways, which may be crucial in tumorigenesis and metastasis. Moreover, research concerning the targeting of miRNAs in vitro and in vivo has demonstrated amazing results in altering the features of pancreatic cancer invasion and metastasis. Various related miRNAs affect pancreatic cancer invasion and metastasis through the regulation of the EMT process, cancer stem cell properties, and tumor-associated signaling pathways, while epigenetic modification may be an important mechanism causing dysregulation of miRNA expression. Therefore, detailed exploration of miRNA molecular mechanisms not only contributes to the understanding of the origin of the highly metastatic properties of pancreatic cancer, but may also provide insight for the improvement of the prognosis for this fatal disease.

\section{Acknowledgements}

This study was supported by National Natural Science Foundation of China grants (Nos. 81172276 and 81001058).

\section{References}

1. Jemal A, Siegel R, Xu J and Ward E: Cancer statistics, 2010. CA Cancer J Clin 60: 277-300, 2010.

2. Zuckerman DS and Ryan DP: Adjuvant therapy for pancreatic cancer: a review. Cancer 112: 243-249, 2008

3. Esquela-Kerscher A and Slack FJ: Oncomirs - microRNAs with a role in cancer. Nat Rev Cancer 6: 259-269, 2006.

4. Denli AM, Tops BB, Plasterk RH, Ketting RF and Hannon GJ: Processing of primary microRNAs by the microprocessor complex. Nature 432: 231-235, 2004.

5. Wightman B, Ha I and Ruvkun G: Posttranscriptional regulation of the heterochronic gene lin-14 by lin- 4 mediates temporal pattern formation in C. elegans. Cell 75: 855-862, 1993.

6. Reinhart BJ, Slack FJ, Basson M, et al: The 21-nucleotide let-7 RNA regulates developmental timing in Caenorhabditis elegans. Nature 403: 901-906, 2000.

7. Calin GA, Dumitru CD, Shimizu M, et al: Frequent deletions and down-regulation of micro-RNA genes miR15 and miR16 at 13 q14 in chronic lymphocytic leukemia. Proc Natl Acad Sci USA 99: 15524-15529, 2002.

8. Bloomston M, Frankel WL, Petrocca F, et al: microRNA expression patterns to differentiate pancreatic adenocarcinoma from normal pancreas and chronic pancreatitis. JAMA 229: 1901-1908, 2007.

9. Lee JW, Choi CH, Choi JJ, et al: Altered microRNA expression in cervical carcinomas. Clin Cancer Res 14: 2535-2542, 2008.

10. Iorio MV, Ferracin M, Liu CG, et al: MicroRNA gene expression deregulation in human breast cancer. Cancer Res 65: 7065-7070, 2005.

11. Budhu A, Jia HL, Forgues M, et al: Identification of metastasisrelated microRNAs in hepatocellular carcinoma. Hepatology 47 897-907, 2008

12. Ma L, Teruya-Feldstein J and Weinberg RA: Tumour invasion and metastasis initiated by microRNA-10b in breast cancer. Nature 449: 682-688, 2007.

13. Meng F, Henson R, Wehbe-Janek H, Ghoshal K, Jacob ST and Patel T: MicroRNA-21 regulates expression of the PTEN tumor suppressor gene in human hepatocellular cancer. Gastroenterology 133: 647-658, 2007.

14. Asangani IA, Rasheed SA, Nikolova DA, et al: MicroRNA-21 (miR-21) post-transcriptionally downregulates tumor suppressor Pdcd4 and stimulates invasion, intravasation and metastasis in colorectal cancer. Oncogene 27: 2128-2136, 2008.
15. Lin SL, Chiang A, Chang D and Ying SY: Loss of mir-146a function in hormone-refractory prostate cancer. RNA 14: 417-424, 2008

16. Crawford M, Brawner E, Batte K, et al: MicroRNA-126 inhibits invasion in non-small cell lung carcinoma cell lines. Biochem Biophys Res Commun 373: 607-612, 2008.

17. Huang Q, Gumireddy K, Schrier M, et al: The microRNAs miR-373 and miR-520c promote tumour invasion and metastasis. Nat Cell Biol 10: 202-210, 2008.

18. Hwang JH, Voortman J, Giovannetti E, et al: Identification of microRNA-21 as a biomarker for chemoresistance and clinical outcome following adjuvant therapy in resectable pancreatic cancer. PloS One 5: e10630, 2010.

19. Giovannetti E, Funel N, Peters GJ, et al: MicroRNA-21 in pancreatic cancer: correlation with clinical outcome and pharmacologic aspects underlying its role in the modulation of gemcitabine activity. Cancer Res 70: 4528-4538, 2010.

20. Moriyama T, Ohuchida K, Mizumoto K, et al: MicroRNA-21 modulates biological functions of pancreatic cancer cells including their proliferation, invasion, and chemoresistance. Mol Cancer Ther 8: 1067-1074, 2009.

21. Bhaumik D, Scott GK, Schokrpur S, Patil CK, Campisi J and Benz CC: Expression of microRNA-146 suppresses NF-kappaB activity with reduction of metastatic potential in breast cancer cells. Oncogene 27: 5643-5647, 2008.

22. Kogo R, Mimori K, Tanaka F, Komune S and Mori M: Clinical significance of miR-146a in gastric cancer cases. Clin Cancer Res 17: 4277-4284, 2011.

23. Fujioka S, Sclabas GM, Schmidt C, et al: Function of nuclear factor kappaB in pancreatic cancer metastasis. Clin Cancer Res 9: 346-354, 2003.

24. Karin M: Nuclear factor-kappaB in cancer development and progression. Nature 441: 431-436, 2006.

25. Li Y, Vandenboom TG II, Wang Z, et al: miR-146a suppresses invasion of pancreatic cancer cells. Cancer Res 70: 1486-1495, 2010.

26. Lin F, Wang X, Jie Z, et al: Inhibitory effects of miR-146b-5p on cell migration and invasion of pancreatic cancer by targeting MMP16. J Huazhong Univ Sci Technolog Med Sci 31: 509-514, 2011.

27. Ma Y, Yu S, Zhao W, Lu Z and Chen J: miR-27a regulates the growth, colony formation and migration of pancreatic cancer cells by targeting Sprouty2. Cancer Lett 298: 150-158, 2010.

28. Yu J, Ohuchida K, Mizumoto K, et al: MicroRNA, hsa-miR-200c, is an independent prognostic factor in pancreatic cancer and its upregulation inhibits pancreatic cancer invasion but increases cell proliferation. Mol Cancer 9: 169, 2010.

29. Wang F, Xue X, Wei J, et al: hsa-miR-520h downregulates ABCG2 in pancreatic cancer cells to inhibit migration, invasion, and side populations. Br J Cancer 103: 567-574, 2010.

30. Preis M, Gardner TB, Gordon SR, et al: MicroRNA-10b expression correlates with response to neoadjuvant therapy and survival in pancreatic ductal adenocarcinoma. Clin Cancer Res 17: 5812-5821, 2011.

31. Srivastava SK, Bhardwaj A, Singh S, et al: MicroRNA-150 directly targets MUC4 and suppresses growth and malignant behavior of pancreatic cancer cells. Carcinogenesis 32: 1832-1839, 2011.

32. Yu J, Ohuchida K, Mizumoto K, Fujita H, Nakata K and Tanaka M: MicroRNA miR-17-5p is overexpressed in pancreatic cancer, associated with a poor prognosis, and involved in cancer cell proliferation and invasion. Cancer Biol Ther 10: 748-757, 2010.

33. Muniyappa MK, Dowling P, Henry M, et al: MiRNA-29a regulates the expression of numerous proteins and reduces the invasiveness and proliferation of human carcinoma cell lines. Eur J Cancer 45: 3104-3118, 2009.

34. Yan H, Wu J, Liu W, et al: MicroRNA-20a overexpression inhibited proliferation and metastasis of pancreatic carcinoma cells. Hum Gene Ther 21: 1723-1734, 2010.

35. Hamada S, Satoh K, Fujibuchi W, et al: MiR-126 acts as a tumor suppressor in pancreatic cancer cells via the regulation of ADAM9. Mol Cancer Res 10: 3-10, 2012.

36. Li W, Yuan Y, Huang L, Qiao M and Zhang Y: Metformin alters the expression profiles of microRNAs in human pancreatic cancer cells. Diabetes Res Clin Pract 96: 187-195, 2012.

37. Thiery JP, Acloque H, Huang RY and Nieto MA: Epithelialmesenchymal transitions in development and disease. Cell 139: 871-890, 2009.

38. Thiery JP and Sleeman JP: Complex networks orchestrate epithelial-mesenchymal transitions. Nat Rev Mol Cell Biol 7: 131-142, 2006. 
39. Christiansen JJ and Rajasekaran AK: Reassessing epithelial to mesenchymal transition as a prerequisite for carcinoma invasion and metastasis. Cancer Res 66: 8319-8326, 2006.

40. Xiong H, Hong J, Du W, et al: Roles of STAT3 and ZEB1 proteins in E-cadherin down-regulation and human colorectal cancer epithelial-mesenchymal transition. J Biol Chem 287: 5819-5832, 2012.

41. Maier HJ, Schmidt-Strassburger U, Huber MA, Wiedemann EM, Beug $\mathrm{H}$ and Wirth T: NF-kappaB promotes epithelialmesenchymal transition, migration and invasion of pancreatic carcinoma cells. Cancer Lett 295: 214-228, 2010.

42. Spaderna S, Schmalhofer O, Wahlbuhl M, et al: The transcriptional repressor ZEB1 promotes metastasis and loss of cell polarity in cancer. Cancer Res 68: 537-544, 2008.

43. Korpal M,Lee ES, Hu G and Kang Y: The miR-200 family inhibits epithelial-mesenchymal transition and cancer cell migration by direct targeting of E-cadherin transcriptional repressors ZEB1 and ZEB2. J Biol Chem 283: 14910-14914, 2008.

44. Burk U, Schubert J, Wellner U, et al: A reciprocal repression between ZEB1 and members of the miR-200 family promotes EMT and invasion in cancer cells. EMBO Rep 9: 582-589, 2008

45. Wellner U, Schubert J, Burk UC, et al: The EMT-activator ZEB1 promotes tumorigenicity by repressing stemness-inhibiting microRNAs. Nat Cell Biol 11: 1487-1495, 2009.

46. Torrisani J, Bournet B, du Rieu MC, et al: let-7 microRNA transfer in pancreatic cancer-derived cells inhibits in vitro cell proliferation but fails to alter tumor progression. Hum Gene Ther 20: 831-844, 2009.

47. Ali S, Almhanna K, Chen W, Philip PA and Sarkar FH: Differentially expressed miRNAs in the plasma may provide a molecular signature for aggressive pancreatic cancer. Am J Transl Res 3: 28-47, 2010.

48. Li Y, VandenBoom TG II, Kong D, et al: Up-regulation of miR-200 and let-7 by natural agents leads to the reversal of epithelial-to-mesenchymal transition in gemcitabine-resistant pancreatic cancer cells. Cancer Res 69: 6704-6712, 2009.

49. Wicha MS, Liu S and Dontu G: Cancer stem cells: an old idea - a paradigm shift. Cancer Res 66: 1883-1890; discussion 1895-1896, 2006.

50. Bonnet D and Dick JE: Human acute myeloid leukemia is organized as a hierarchy that originates from a primitive hematopoietic cell. Nat Med 3: 730-737, 1997.

51. Singh SK, Hawkins C, Clarke ID, et al: Identification of human brain tumour initiating cells. Nature 432: 396-401, 2004.

52. Al-Hajj M, Wicha MS, Benito-Hernandez A, Morrison SJ and Clarke MF: Prospective identification of tumorigenic breast cancer cells. Proc Natl Acad Scie USA 100: 3983-3988, 2003.

53. O'Brien CA, Pollett A, Gallinger S and Dick JE: A human colon cancer cell capable of initiating tumour growth in immunodeficient mice. Nature 445: 106-110, 2007.

54. Li C, Heidt DG, Dalerba P, et al: Identification of pancreatic cancer stem cells. Cancer Res 67: 1030-1037, 2007.

55. Hermann PC, Huber SL, Herrler T, et al: Distinct populations of cancer stem cells determine tumor growth and metastatic activity in human pancreatic cancer. Cell Stem Cell 1: 313-323, 2007.

56. Moriyama T, Ohuchida K, Mizumoto K, et al: Enhanced cell migration and invasion of $\mathrm{CD} 133^{+}$pancreatic cancer cells cocultured with pancreatic stromal cells. Cancer 116: 3357-3368, 2010.

57. May R, Sureban SM, Lightfoot SA, et al: Identification of a novel putative pancreatic stem/progenitor cell marker DCAMKL-1 in normal mouse pancreas. Am J Physiol Gastrointest Liver Physiol 299: G303-310, 2010.

58. Sureban SM, May R, Lightfoot SA, et al: DCAMKL-1 regulates epithelial-mesenchymal transition in human pancreatic cells through a miR-200a-dependent mechanism. Cancer Res 71: $2328-2338,2011$

59. Tarasov V, Jung P, Verdoodt B, et al: Differential regulation of microRNAs by $\mathrm{p} 53$ revealed by massively parallel sequencing. miR-34a is a p53 target that induces apoptosis and G1-arrest. Cell Cycle 6: 1586-1593, 2007.

60. Bommer GT, Gerin I, Feng Y, et al: p53-mediated activation of miRNA34 candidate tumor-suppressor genes. Curr Biol 17: $1298-1307,2007$

61. Ji Q, Hao X, Zhang M, et al: MicroRNA miR-34 inhibits human pancreatic cancer tumor-initiating cells. PloS One 4: e6816, 2009.

62. Ji Q, Hao X, Meng Y, et al: Restoration of tumor suppressor miR-34 inhibits human p53-mutant gastric cancer tumorspheres. BMC Cancer 8: 266, 2008.
63. Bao B, Ali S, Banerjee S, et al: Curcumin analogue CDF inhibits pancreatic tumor growth by switching on suppressor microRNAs and attenuating EZH2 expression. Cancer Res 72: 335-345, 2012

64. Wang Z, Li Y, Banerjee S and Sarkar FH: Emerging role of Notch in stem cells and cancer. Cancer Lett 279: 8-12, 2009.

65. Demarest RM, Ratti F and Capobianco AJ: It's T-ALL about Notch. Oncogene 27: 5082-5091, 2008.

66. Dotto GP: Notch tumor suppressor function. Oncogene 27: 5115-5123, 2008

67. Wang Z, Banerjee S, Li Y, Rahman KM, Zhang Y and Sarkar FH: Down-regulation of notch-1 inhibits invasion by inactivation of nuclear factor-kappaB, vascular endothelial growth factor, and matrix metalloproteinase-9 in pancreatic cancer cells. Cancer Res 66: 2778-2784, 2006.

68. Strizzi L, Hardy KM, Seftor EA, et al: Development and cancer: at the crossroads of Nodal and Notch signaling. Cancer Res 69: 7131-7134, 2009.

69. Ristorcelli E and Lombardo D: Targeting Notch signaling in pancreatic cancer. Expert Opin Ther Targets 14: 541-552, 2010.

70. Nalls D, Tang SN, Rodova M, Srivastava RK and Shankar S: Targeting epigenetic regulation of miR-34a for treatment of pancreatic cancer by inhibition of pancreatic cancer stem cells. PloS One 6: e24099, 2011

71. Bao B, Wang Z, Ali S, et al: Notch-1 induces epithelial-mesenchymal transition consistent with cancer stem cell phenotype in pancreatic cancer cells. Cancer Lett 307: 26-36, 2011.

72. Matthaios D, Zarogoulidis P, Balgouranidou I, Chatzaki E and Kakolyris S: Molecular pathogenesis of pancreatic cancer and clinical perspectives. Oncology 81: 259-272, 2011.

73. Feldmann G, Dhara S, Fendrich V, et al: Blockade of hedgehog signaling inhibits pancreatic cancer invasion and metastases: a new paradigm for combination therapy in solid cancers. Cancer Res 67: 2187-2196, 2007.

74. Ferretti E, De Smaele E, Miele E, et al: Concerted microRNA control of Hedgehog signalling in cerebellar neuronal progenitor and tumour cells. EMBO J 27: 2616-2627, 2008.

75. Northcott PA, Fernandez LA, Hagan JP, et al: The miR-17/92 polycistron is up-regulated in sonic hedgehog-driven medulloblastomas and induced by $\mathrm{N}$-myc in sonic hedgehog-treated cerebellar neural precursors. Cancer Res 69: 3249-3255, 2009.

76. Friggi-Grelin F, Lavenant-Staccini L and Therond P: Control of antagonistic components of the hedgehog signaling pathway by microRNAs in Drosophila. Genetics 179: 429-439, 2008.

77. Tsuda N, Ishiyama S, Li Y, Ioannides CG, Abbruzzese JL and Chang DZ: Synthetic microRNA designed to target gliomaassociated antigen 1 transcription factor inhibits division and induces late apoptosis in pancreatic tumor cells. Clin Cancer Res 12: 6557-6564, 2006.

78. Yu S, Lu Z, Liu C, et al: miRNA-96 suppresses KRAS and functions as a tumor suppressor gene in pancreatic cancer. Cancer Res 70: 6015-6025,2010.

79. Vogt M, Munding J, Gruner M, et al: Frequent concomitant inactivation of miR-34a and $\mathrm{miR}-34 \mathrm{~b} / \mathrm{c}$ by $\mathrm{CpG}$ methylation in colorectal, pancreatic, mammary, ovarian, urothelial, and renal cell carcinomas and soft tissue sarcomas. Virchows Arch 458: 313-322, 2011.

80. Tashiro E, Tsuchiya A and Imoto M: Functions of cyclin D1 as an oncogene and regulation of cyclin D1 expression. Cancer Sci 98: 629-635, 2007.

81. Lee KH, Lotterman C, Karikari C, et al: Epigenetic silencing of MicroRNA miR-107 regulates cyclin-dependent kinase 6 expression in pancreatic cancer. Pancreatology 9: 293-301, 2009.

82. Grewal IS and Flavell RA: CD40 and CD154 in cell-mediated immunity. Annu Rev Immunol 16: 111-135, 1998.

83. Costello RT, Gastaut JA and Olive D: What is the real role of CD40 in cancer immunotherapy? Immunology Today 20: 488-493, 1999

84. Mees ST, Mardin WA, Sielker S, et al: Involvement of CD40 targeting miR-224 and miR-486 on the progression of pancreatic ductal adenocarcinomas. Ann Surg Oncol 16: 2339-2350, 2009.

85. Kouzarides T: Histone acetylases and deacetylases in cell proliferation. Curr Opin Genet Dev 9: 40-48, 1999.

86. Ida K, Kitabayashi I, Taki T, et al: Adenoviral E1A-associated protein $\mathrm{p} 300$ is involved in acute myeloid leukemia with $\mathrm{t}(11 ; 22)$ (q23;q13). Blood 90: 4699-4704, 1997.

87. Mees ST, Mardin WA, Wendel C, et al: EP300 - a miRNAregulated metastasis suppressor gene in ductal adenocarcinomas of the pancreas. Int J Cancer 126: 114-124, 2010. 